\title{
A DEA Approach towards to the Evaluation of loT Applications in Intelligent Ports
}

\author{
Guo-Ya Gan \\ College of Auditing and Evaluation, Nanjing Audit University, Nanjing, Jiangsu, China
}

Hsuan-Shih Lee

Department of Shipping and Transportation Management, National Taiwan Ocean University, Keelung, Taiwan, R.O.C., hslee@email.ntou.edu.tw

Jia-Yi Liu

School of Marine Science and Technology, Tianjin University, Tianjin, China

Follow this and additional works at: https://jmstt.ntou.edu.tw/journal

Part of the Operational Research Commons, and the Operations and Supply Chain Management Commons

\section{Recommended Citation}

Gan, Guo-Ya; Lee, Hsuan-Shih; and Liu, Jia-Yi (2021) "A DEA Approach towards to the Evaluation of IoT Applications in Intelligent Ports," Journal of Marine Science and Technology. Vol. 29: Iss. 3, Article 2.

DOI: $10.51400 / 2709-6998.1431$

Available at: https://jmstt.ntou.edu.tw/journal/vol29/iss3/2

This Research Article is brought to you for free and open access by Journal of Marine Science and Technology. It has been accepted for inclusion in Journal of Marine Science and Technology by an authorized editor of Journal of Marine Science and Technology. 


\section{A DEA Approach towards to the Evaluation of IoT Applications in Intelligent Ports}

\section{Acknowledgements}

This research is partially supported by the Key Project in Philosophy and Social Science Research of Ministry of Education of China (18JZD059), and the natural science research project of the university in Jiangsu province (19KJB120009). The authors are also grateful for the comments and suggestions provided by anonymous reviewers. 


\title{
A DEA Approach Towards to the Evaluation of IoT Applications in Intelligent Ports
}

\author{
Guo-Ya Gan $^{a, *}$, Hsuan-Shih Lee ${ }^{\mathrm{b}, \mathrm{c}, * *}$, Jia-Yi Liu $^{\mathrm{d}}$

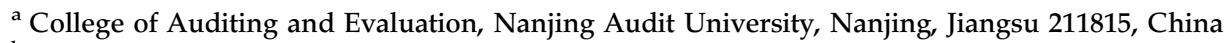 \\ ${ }^{\mathrm{b}}$ Department of Shipping and Transportation Management, National Taiwan Ocean University, Keelung 20224, Taiwan, R.O.C \\ ${ }^{c}$ Department of Information Management, Ming Chuan University, Taipei 11103, Taiwan, R.O.C \\ ${ }^{\mathrm{d}}$ School of Marine Science and Technology, Tianjin University, Tianjin 300072, China
}

\begin{abstract}
Driven by the development of world's technology, the concept of Internet of things (IoT) not only promotes the leapfrog development of global information technology, but also makes computer and communication technology realize further perfection. IoT technology enables the global sharing of network resources and the overall perception of information to achieve the goal of "interconnection of all things together," which is the third wave of world's information industry development after the computer and Internet. Recently, the rapid expansion of IoT technology has made many conventional industries more intelligent. With the accelerated expansion of port traffic, many conventional ports are facing the transformation of operation mode. They urgently need to improve the service quality of infrastructure, comprehensive processing capacity for information and the optimized allocation of resources of their related logistics parks. Therefore, from the aspects of intelligent supervision, intelligent service and technology security, this study constructs the data envelopment analysis (DEA) framework of factors influencing the intelligent transformation of international commercial ports with the application of IoT technology. This study hopes to help port managers to improve the operational performance through an intelligent cloud connection, and to transform conventional port to intelligent commercial port 4.0 as soon as possible.
\end{abstract}

Keywords: Internet of things (IoT), Data envelopment analysis (DEA), Intelligent ports, Key success factor framework

\section{Introduction}

I $\mathrm{n}$ an era of global economic interconnectedness and commercial interconnectedness, the world is becoming more and more interconnected through technological advances. As the benefits of system resource integration are explored and understood, the living environment affected by the world's intelligent innovation is also gradually promoted. The concept of intelligent equipment networking as early as in 1982 was discussed, and a group of students at Carnegie Mellon University developed a network system to sell coke. Through this new network technology, at any time, managers can be provided the information about the inventory of coke in the refrigerator and whether the new beverage has been frozen. The network system has achieved the timely and efficient information exchange by connecting the coke selling machine and manager. For this reason, this machine is also known as the first network intelligent home appliances, and inspired researchers for the transformation and innovation of future intelligent machines. This event also became the enlightenment of the concept of the Internet of Things (IoT), which can be described

Received 11 June 2020; revised 8 July 2020; accepted 27 July 2020.

Available online 25 June 2021.

* Corresponding author.

** Corresponding author.

E-mail addresses: ganguoya@foxmail.com (G.-Y. Gan), hslee@email.ntou.edu.tw (H.-S. Lee).

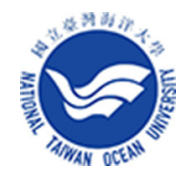


as with the 'link' as the foundation, IoT system can connect objects in some form and carry out the exchange of data between these objects. Wired connectivity is inherently not suited to the complex or large-scale network system, so wireless technology is widely used by IoT to connect objects more intelligently [1].

The emergence of IoT is a new technological revolution in the field of computing and communications, which also can be expanded into some other important areas, such as dynamic communications, technological innovation, wireless sensors and nanotechnology, etc $[2,3]$. Frequently, the produced data of the IoT system plays a vital role, and these critical data mainly depends on the perception of IoT devices of various types of sensors in this system. Then, IoT system perceives consumer behavior and experiencers' consumption habits. These recorded data will be transferred to the computing center, and dealing with cloud computing and big data processing, the final effective research data can be formed [4]. These research data will be fed back to the management side in time, which hopes to help service providers improve their own shortcomings and provide more customized comfortable services for those experiencing them. Therefore, according to the rich and invisibly interwoven elements of sensors, actuators, displays, and cloud computing, IoT system has perfectly integrated into the objects of our daily lives and connected everything through a continuous network structure in the real producing process. This intelligent system brings the convenience to people's travel, production and living, which can also constitute people's pursuit of the intelligent living environment.

The composition of the IoT system is never a single individual, which is usually composed of numerous data sensors, receivers and other devices [5]. In this way, the network system constituted by a number of intelligent interconnected devices also highlights its value and advantages in real life. First of all, the IoT system realizes the information exchange between the different objects, which highlights its value in terms of information exchanging. Devices in the IoT system can always use the same IP address of the Internet for the information exchange, so there will be no additional energy consumption during the data exchanging period [6]. Second, IoT system creates more economic value for people's real life. The applications of IoT can significantly reduce the labour costs, time cost, transportation costs, etc. Based on the existing network infrastructure, IoT system achieves the implementation effect of product integration. Under the premise of it without any increase in new equipment, this intelligent network system is greatly saving the operating costs through using the existing facilities to satisfy the requirements of the intelligent production. Finally, the prospect of the value of IoT applications is also very substantial. The international telecommunication union (ITU) of the United Nations ever published one report on IoT, which pointed out that after the innovation of information and communication technology, IoT becomes the third wave of the world's information industry development and has quietly catch the attention across the globe. Any person at any time, any place, for any things will be connected, and the connection presents the increase of the multiple, so as to create a new intelligent dynamic network, that is the prospect value and advantage of the IoT applications. The development of IoT system will affect the logistics, public management, international ports, finance, industrial manufacturing, retail, education, and other different industries [7]. And rely on the advantages of timely feedback by itself, IoT system can also significantly help managers save time costs and reduce some unanticipated losses.

Along with the new innovation of information technology, intelligent devices are more easily to connect sensors and user experience port through the network, which can construct more convenient application service programs for its users [8]. These innovative technological changes have also laid an excellent environmental foundation for the establishment of the IoT system. Besides, the related research is becoming increasingly perfect, and it is expected that more and more applications of the IoT system will grow rapidly in the next few years. In fact, we can also find many practical applications of the IoT system in our real life, such as the Internet of Vehicles.

The construction of vehicle network can not only help the owners to find the nearest parking lot in the bustling city and provide the information about the spare parking space, but also allow the owner to track and locate their cars at any time, so as to find the car as quickly as possible in one huge underground parking garage, and guide the owner to drive out of this parking lot. The similar case also appears in the promotion of intelligent home, and the users can remotely control their water heater through a smartphone before arriving home. It reveals that in addition to the smartphone, other existing devices are also likely to be utilized by the IoT system, such as networked televisions, LED lighting systems in buildings, and central air conditioning equipment [9]. To this end, based on the 
advantage of the high utilization of existing networked devices, applying the IoT system has become the best opportunity for the transformation of many conventional industries. To these industries, the high cost of the equipment makes it a slow replacement cycle. With the acceleration of international liquidity in commodities, many conventional industries have to face the double pressures of improving the productions and transportation efficiency. Nowadays, the urgent need for the relevant managers is how to rationally use or innovate on the existing equipment, which can help the conventional industry enhance more international competitiveness. And the international commercial port is one of the crucial demanders of these conventional industries [10].

International commercial ports are usually the gateway and hub for a country opening to the outside world, and they are closely related to the economic development of many coastal countries [11]. Thus, the intelligent transformation of the commercial ports has become one of the critical topics that attracted strong attention by the leaders of many countries, such as China, the world's second-largest economy. During the visit to Tianjin port in 2019, President Xi stressed that before the social economic development and national strength enhancement, the international and domestic transportation should be strengthened first, especially in the development of sea transportation. Striving to build a world-class "intelligent and green port," and work together with other countries to implement the construction of the "One Belt And One Road." The "intelligent port" mentioned by President $\mathrm{Xi}$ refers to the utilization of modern infrastructure equipment, combing with the massive data, cloud computing, intelligent control, and other real information technology, to achieve the core task of deeply integration on port transport business. At the same time, driven by the innovation of port transportation organization services, the intelligent automation of port production and operation, the modernization of port infrastructure and equipment, intelligence decision-making of port management, and the sensitivity of port transportation services can be realized. These requirements reveal that the development of intelligent production and intelligent management in the concept of "intelligent port" are closely related to the unique characteristics of the IoT system. Applying the intelligent system to the port's operating management is bound to contribute an un-underestimated power to the successful transformation of international commercial ports [10].
To this end, from the perspective of the promotion of IoT system in international commercial ports, this study hopes to explore and evaluate the key success factors that affect the value realization of IoT system in international commercial port operation. In further, some suggestions may help the corresponding managers optimize the allocation of port resources and improve the port services to a higher and more efficient quality. The structure of this paper is as follows: Section 2 reviews the literature about the applications of IoT system in different filed and the researches of applying IoT system to the international commercial ports in recent years. Section 3 introduces both of the SBM (slack-based measure) model and super-SBM model of DEA to evaluate the key success factors affecting the realization of IoT system in international commercial port. A new framework of factors is constructed in Section 4, and the interview process and data analysis of expert questionnaire are also described in detail. The last section presents the conclusions of this study.

\section{Literature Review}

The IoT system is increasingly being used to manage and monitor the working status of the operating process at any time, which makes it much easier to communicate remotely with things around the world. This emerging technology is booming around the world, and transforming many conventional industries into the digital intelligent pattern. To this end, many researches related IoT applications have been rapidly expanded in recent years [12-17]. IoT system is a relatively new and growing field, which helps conventional manufacturing companies quickly respond to the global competitive pressures by adopting the new data-driven strategy [18]. showed the adoption approach that IoT system takes both perception systems and mobile devices into account to produce the final industrial big data in the field of manufacturing. One practical case study of a moldmaking industry is utilized to validate the effectiveness of the proposed methodology [19]. proposed the semantic interoperability model for the application of IoT devices in health care, which help to choose the effective medicine based upon the different symptoms. The data collected from heterogeneous sensors of IoT system can be transferred to the critical information in one meaningful way between patient and physician. A proposed lightweight model for dealing with the semantic annotation of big-data can also reduce the major burden of physicians, which rationalizes the great 
heterogeneity in the primary communication protocols, technologies and data formats. Services of IoT system in intelligent home energy management is another critical application platform [20]. explored the influence of various perceived risks (such as perceived security risk, financial risk) and individual propensities (acceptance on new technology, changes of electricity price) under the overall risk perception of IoT home services. Their research points out that the experiencers are more likely to be fear of the electromagnetic radiation. Still, cyber-security threat is one of the weak links on IoT home service that should be paid more attentions. They also indicate that their study results are not only useful for the stake-holders marketing IoT service to consumers, but also for the researches on technology acceptance and perceived risk [21]. focused their study on the traffic problems in people's daily travel. In real life, when a large number of IoT devices sending the communication codes to the same base receiver at the same time, it is easy to lead to a sudden surge of research data and cause conflicts, which may also result in some serious network congestion. A communication timing controlling approach is proposed for the temporal and space transportation offloading. A case of comparative evaluation demonstrates the effectiveness of their proposed approach. Besides, due to the rich application scenarios, retail industry is also one of the hot research areas of IoT applications [22]. drew the attention to monitor gray market activity and manage the gray product distribution by adopting the IoT system. Three game models are established to examine the impact of IoT system on manufacturer's profits and the gray market. The final results reveal that IoT system has a significant influence on inhibiting the growth of the gray market, and the final win-win performance can be acquired when the manufacturers are taking the appropriate coping strategy.

For many countries, international commercial ports are the main windows opening to the world. Both the origin and economy of this nation are clearly linked to the existing development of these ports. But in recent years, many problems stifle their growth, such as delays in the arrival of carrying truck and the traffic jams on port's transporting roads [23]. IoT system can usually realize the digitalization of transportation infrastructure in port, the standardization and intelligence of port transportation equipment and the efficient integration of port resources. However, the study applying the IoT system to international commercial ports is little [24]. pointed out that the trade volume of sea transportation is growing around the world, resulting in the increasing loading press on the port's road infrastructures. It's urgent to propose new solutions to improve the cargo coordination and handling capacity of the existing port facilities. A digital binary model assisted by the truck dispatching operator is proposed to optimize the problems of the equipment dispatching management in the port. Finally, combing with the IoT platform and an extensible simulation package, the integration of all sensor information can be utilized to improve the operating performance of the international commercial ports [25]. also focused their study on the optimizing the management and monitoring the container traffic in the harbor along the intermodal corridor. Based upon one cloud-based FIWARE platform, a new IoT system is constructed to integrate the management of the vessel navigation and the rail transportation. More importantly, three internal sub-systems (including container loading, inland vessel navigation, and rail transportation) have produced the expected benefits in port's supply chain, which covers the benefits of both ship owners and the terminal integration in the port's logistics.

Recently, the development of IoT system represents a new step in transforming the conventional international commercial ports to an automated, intelligent and digital operation pattern. It is also a unique starting point for the IoT system expanding to the field of port management, which should catch more attention by scholars. Therefore, this study will construct a new framework of factors influencing the intelligent transformation of international commercial ports with IoT system. Combing with the SBM-DEA and super-SBM-DEA models, this study further hopes to dig out and evaluate the key success factors affecting the value realization of IoT system in international commercial port operation.

\section{Methodology}

Considering the slack-based measure [26], proposed the SBM-DEA model to evaluate $n$ DMUs with multiple inputs and outputs variables. The model under the variable return to scale (VRS) for evaluating the efficiency of DMU- $k$ can be described as: 


$$
\begin{aligned}
& \min \varpi=\frac{1-\frac{1}{m} \sum_{i=1}^{m} w_{i}^{-} / x_{i k}}{1+\frac{1}{s} \sum_{r=1}^{s} w_{r}^{+} / y_{r k}} \\
& \text { s.t. } \quad \sum_{j=1}^{n} x_{i j} \lambda_{j}=x_{i k}-w_{i}^{-}, \quad i=1, \ldots, m ; \\
& \quad \sum_{j=1}^{n} y_{r j} \lambda_{j}=y_{r k}+w_{r}^{+}, \quad r=1, \ldots, s ; \\
& \sum_{j=1}^{n} \lambda_{j}=1 ; \\
& \lambda_{j} \geq 0, \quad j=1, \ldots, n \\
& w_{i}^{-} \geq, \quad i=1, \ldots, m . \\
& w_{r}^{+} \geq, \quad r=1, \ldots, s .
\end{aligned}
$$

However, to the performance evaluation appraisal in the real life, there are many cases that existing no specific input variables or these variables are difficult to measure. For dealing with this issue, the evaluation results of experts can be viewed as the output variables while none input variable can be considering in this study. Thus, suppose there are $n$ evaluated factors and the number of experts is $s$ in this study. Let $x_{j}$ denotes the dummy input while $y_{r j}(j=1, \ldots, n)$ denotes the evaluation result of $r$ th expert for the $j$ th evaluated factor. To evaluate the efficiency of the $k$ th evaluated factor, Model (1) can be modified as:

$$
\begin{aligned}
& \min \varpi=\frac{1-\frac{w^{-}}{x_{k}}}{1+\frac{1}{s} \sum_{r=1}^{s} w_{r}^{+} / y_{r k}} \\
& \text { s.t. } \quad \sum_{j=1}^{n} x_{j} \lambda_{j}=x_{k}-w^{-} ; \\
& \sum_{j=1}^{n} y_{r j} \lambda_{j}=y_{r k}+w_{r}^{+}, \quad r=1, \ldots, s ; \\
& \sum_{j=1}^{n} \lambda_{j}=1 ; \\
& \lambda_{j} \geq 0, j=1, \ldots, n ; \\
& w^{-} \geq 0 ; \\
& w_{r}^{+} \geq 0, \quad r=1, \ldots, s .
\end{aligned}
$$

where $w^{-}$denotes the surplus of input variables while $w_{r}^{+}$denote the deficiency of output variables. Let the values of all dummy input $x_{j}$ be 1 in this study. And due to the limitation of $\sum_{j=1}^{n} \lambda_{j}=1$, the first constraint can be deleted and the object function of model (2) can also be modified.

$$
\begin{array}{ll}
\min & \rho=\frac{1}{1+\frac{1}{s} \sum_{r=1}^{s} w_{r}^{+} / y_{r k}} \\
\text { s.t. } & \sum_{j=1}^{n} y_{r j} \lambda_{j}=y_{r k}+w_{r}^{+}, \quad r=1, \ldots, s ; \\
& \sum_{j=1}^{n} \lambda_{j}=1 ; \\
& \lambda_{j} \geq 0, \quad j=1, \ldots, n ; \\
& w_{r}^{+} \geq 0, \quad r=1, \ldots, s .
\end{array}
$$

Model (3) can be viewed one simplified version of SBM-DEA model, which is suitable for the database of all DMUs keeping the exactly same original input background. Under the evaluation of model (3), the efficiencies of all efficient units would be calculated as 1 while the ones of un-efficient units would be less than 1. In order to improve the discrimination of model (3), the super-efficiency model based on [27] for the further evaluation of efficient units is proposed as:

$$
\begin{array}{ll}
\min & \phi=\frac{1}{1-\frac{1}{s} \sum_{r=1}^{s} w_{r}^{-} / y_{r k}} \\
\text { s.t. } & \sum_{j=1, j \neq k}^{n} y_{r j} \lambda_{j} \geq y_{r k}-w_{r}^{-}, \quad r=1, \ldots, s ; \\
& \sum_{j=1, j \neq k}^{n} \lambda_{j}=1 ; \\
& \lambda_{j} \geq 0, \quad j=1, \ldots, n, j \neq k ; \\
& y_{r k} \geq w_{r}^{-} \geq 0, \quad r=1, \ldots, s .
\end{array}
$$

where $w_{r}^{-}$denote the surplus of output variables for the efficient DMUs under the model (3). By constructing the new efficient frontier through the remaining DMUs (exclude the evaluated DMU- $k$ ), model (4) can calculate the super-efficiency for the efficient DMUs to above 1 . Further, in this study, we propose a new model to integrating both model (3) 
and model (4), which hopes to compute all the efficiency in one step.

$$
\begin{array}{ll}
\max & \Psi=\left(1+\frac{1}{s} \sum_{r=1}^{s} w_{r}^{+} / y_{r k}\right)+M\left(1-\frac{1}{s} \sum_{r=1}^{s} w_{r}^{-} / y_{r k}\right) \\
\text { s.t. } & \sum_{j=1, j \neq k}^{n} y_{r j} \lambda_{j} \geq y_{r k}+w_{r}^{+}-w_{r}^{-}, \quad r=1, \ldots, s ; \\
& \sum_{j=1, j \neq k}^{n} \lambda_{j}=1 ; \\
& \lambda_{j} \geq 0, \quad j=1, \ldots, n, \quad j \neq k ; \\
& w_{r}^{+} \geq 0, \quad y_{r k} \geq w_{r}^{-} \geq 0, \quad r=1, \ldots, s .
\end{array}
$$

Note that the $M$ in the object function of model (5) is a big data. And suppose one set of the optimal solution is $\left(w_{r}^{+*}, w_{r}^{-*}, \lambda_{j}^{*}\right)$, then, the final efficiencies for the evaluated DMU-k can be calculated as:

$$
E_{k}=\left(\frac{1}{1+\frac{1}{s} \sum_{r=1}^{s} w_{r}^{+*} / y_{r k}}+\frac{1}{1-\frac{1}{s} \sum_{r=1}^{s} w_{r}^{-*} / y_{r k}}\right)-1
$$

For ranking the evaluated key success factors, this study defines the key affecting index (KAI) based on the efficiency performance:

$$
K A I_{k}=\frac{E_{k}}{\operatorname{Max}_{j=1, \ldots, n}\left\{E_{j}\right\}}
$$

\section{Empirical Study}

\subsection{Frame construction}

IoT technology is opening a new stage for the transformation and development of the international commercial ports. Thus, the key success factor system that affects the availability of IoT applications has not been completely established. According to the expert interviews and [17]; this study constructs a new framework with four main categories, namely the technological innovation (TI), support by the government (SG), social and economic values (SEV), experiencer's trust (ET), respectively. And these categories can be further sub-divided into fifteen criteria based upon the invited experts' work experience and the literature review. After the comprehensive discussion, the final framework is established (Shown in Fig. 1), and the specific indicator description of the fifteen criteria can be summarized as:
- Technological innovation (TI)

In this category, all evaluated items mainly refer to the technological development required by the IoT concept and the technological innovation of various supporting devices. Specific indicators include the globalization of data standards (GDS), the construction of open-resource platforms on IoT applications (COP), the development of cloud computing \& Big-data (DCB), the greatly improved speed of data analysis technology (SDA).

\section{- Support by the government (SG)}

In this category, all evaluated items refer to during the whole process of applying the IoT concept to the international commercial ports, and the government promotes the implementation of IoT applications via issuing some beneficial measures. Specific indicators include support by the government funding (SGF), the relevant technical personnel provided by the government (TPG), government actively accedes some international conventions for IoT and maritime transportation (GAC), the active promotion on transformation policy of intelligent port 4.0 (PTP).

\section{- Social and economic values (SEV)}

In this category, all evaluated items refer to the positive social value and economic effects that may be generated or created by the IoT system applying on the international commercial ports, and these innovative values can genuinely benefit people's operation and real life. Specific indicators include improving the operational efficiency of the international commercial ports and the customized service level (IOP), proving more convenient people-oriented services (PCS), integrating the resources of different industries and strengthening the cooperation among enterprises (IR\&SC), guaranteeing the sustainable development of innovative operation strategy (GSD).

\section{- Experiencer's trust (ET)}

In this category, all evaluated items refer to gaining the trust from the experiencer through promulgating some measures to improve the security and convenience of the IoT system. Specific indicators include improving the stability of data transmission during the process of using the IoT system (ISD), guaranteeing the security of the generated results from IoT system (GSR), enhancing the understanding and cognition of IoT system to the port managers (EUC). 


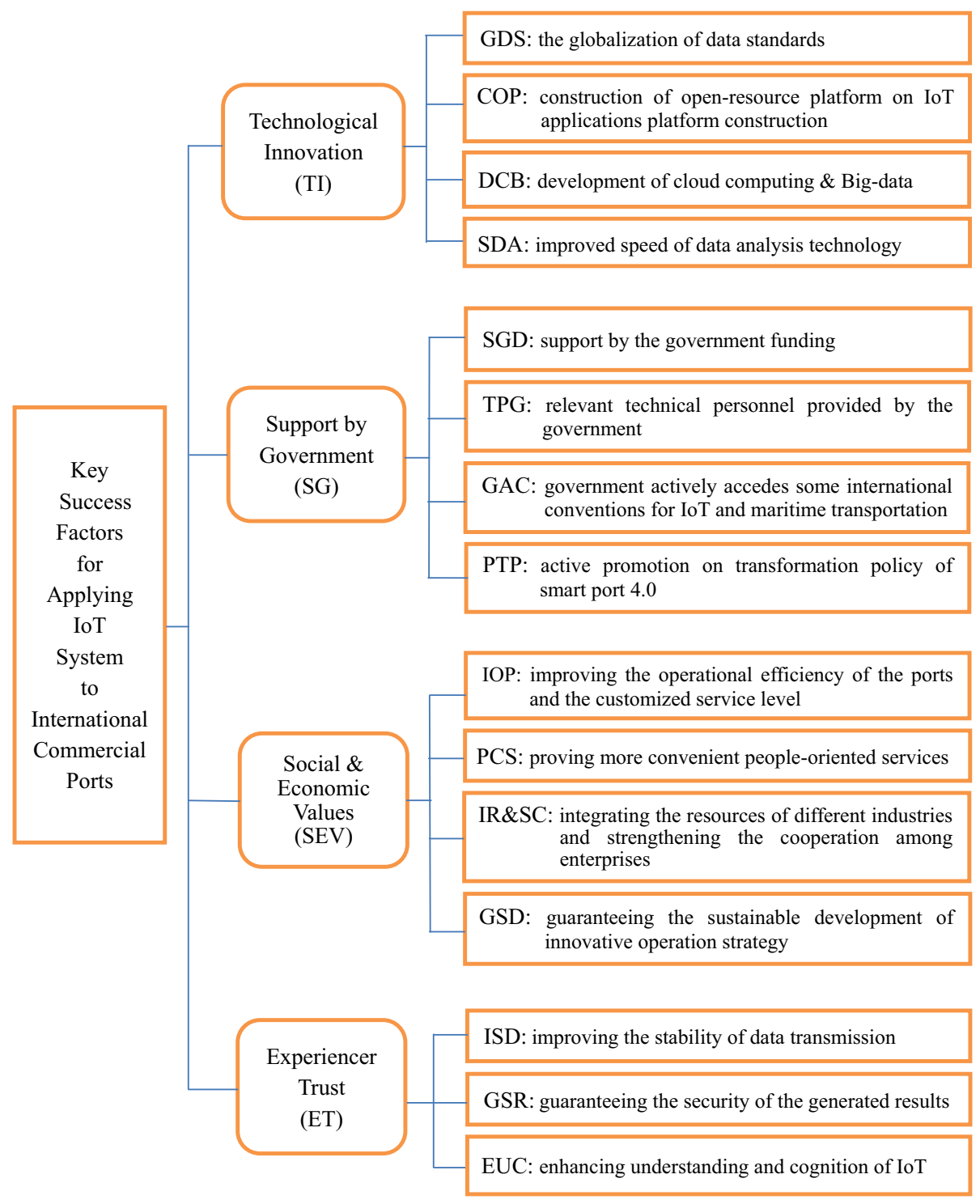

Fig. 1. Framework of key success factors for applying IoT system to international commercial ports.

\subsection{Experts questionnaire survey}

In order to promote the IoT application on port's operation, this study constructs a new framework of the key success factors for applying IoT system to international commercial ports. Fifteen experts are invited to finish this questionnaire, and their evaluation results will be viewed as the key outputs variables of each evaluated factor in this study. The experts are broadly divided into three types based on their experience and the working backgrounds: operation manager in port, related enterprise technicians in IoT industry, and academic scholars.

Table 1 presents the information statistics of the interviewed experts, which indicates that most experts are male, and only a quarter of the respondents are women. The age distribution of interviewed experts shows the relatively normal distribution, and most of the interviewees are ranged from 36 to 50 years $(56.25 \%)$, followed by those aged older than 50 years $(31.25 \%)$. Seniority can reflect the work experience of the interviewers, and over $80 \%$ of the interviewers had worked for more than 10 years, while $43.75 \%$ had worked in related fields for more than 15 years.

\subsection{Evaluation results and analysis}

According to the evaluation of the interviewed experts, this study converts these results presenting the importance levels into the centesimal system. These evaluation results would be selected as the 
output variables for each evaluated sub-criteria. Based on the statistical evaluation results, all evaluated factors have obtained the maximum scores of 100 while the minimize score is 60 . Besides, the Top 3 evaluated factors of the average evaluation results are GDS (92.86), PTP (91.96) and GSD (90.18), respectively. Further, under the model (5), the final results of key affecting index (KAI) and the rankings are summarized in Table 2.

As shown in Table 2, the second column presents the average score of each main category based upon the KAI value of its sub-criteria. From the perspective of expert evaluation, "Support by Government (SG)" should be brought to the most attention with the score of 0.97420 . And the following three categories in order are "Technological Innovation (TI)", "Social \& Economic Values (SEV)", and "Experiencer's Trust (ET)", respectively.

As indicated in Table 2, all of the evaluated criteria have obtained the satisfactory evaluation scores of KAI. Most of them are above 0.9, and the difference between them is not so noticeable. "The Globalization of Data Standards (GDS)" is ranking in the first with the score of 1 , which belongs to the category of "Technological Innovation (TI)." Therefore, most of the experts generally agree that a unified global standard for IoT system is the core factor in guaranteeing the effective implementation of its application. Followed by Active promotion on transformation policy of intelligent port 4.0 (PTP) with a high score of 0.99803 . This criterion can reflect that conventional port is facing the urgent demands of transformation, intelligent ports can not only help managers integrate port resources to improve operation performance, but also strengthen international competitiveness. Besides, "Guaranteeing the sustainable development of innovative operation strategy (GSD)" is the most critical subcriteria of "Social \& Economic Values (SEV)," which
Table 2. Final results of key affecting index (KAI) and the rankings.

\begin{tabular}{lllll}
\hline Main categories & Average \& Rank & Criteria & KAI & Rank \\
\hline TI & $0.97363[2]$ & GDS & 1.00000 & 1 \\
& & COP & 0.96486 & 8 \\
& & DCB & 0.96772 & 5 \\
SG & $0.97420[1]$ & SDA & 0.96196 & 11 \\
& & SGD & 0.96425 & 10 \\
& & TPG & 0.96486 & 8 \\
& & GAC & 0.97156 & 4 \\
SEV & $0.96887[3]$ & PTP & 0.99614 & 2 \\
& & IOP & 0.96772 & 5 \\
& & PCS & 0.96772 & 5 \\
& & IR\&SC & 0.95908 & 14 \\
ET & $0.96005[4]$ & GSD & 0.98097 & 3 \\
& & ISD & 0.96196 & 11 \\
& & GSR & 0.95911 & 13 \\
& & EUC & 0.95908 & 14 \\
\hline
\end{tabular}

is also squeezed into the Top 3 ranking. This criterion advocates the managers to pay more attention to the sustainable development of international commercial ports.

\section{Conclusion}

At present, the innovation in communication technology plays a decisive role in the development of IoT. Especially in the worthy of attention, 5G era is the biggest leap forwarding in communication technology in recent years, which also can provide the efficient technical service platform to support IoT technology to connect everything around the world $[12,28]$. And the realization of $5 \mathrm{G}$ network will definitely promote the rapid expansion of IoT applications. The IoT system combined with 5G network can accommodate more connected objects, and the data collected by the sensing devices will be transmitted more efficiently among the internal structures of this system, so as to realize the goal of connecting everything. The prospect of the IoT system being promoted to commercial use is worth

Table 1. Statistics of the interviewed experts.

\begin{tabular}{|c|c|c|c|c|c|c|}
\hline \multirow[t]{2}{*}{ Experts } & \multicolumn{2}{|c|}{ Industry-related } & \multicolumn{2}{|l|}{ Manager } & \multicolumn{2}{|l|}{ Academic } \\
\hline & Frequency & $\%$ & Frequency & $\%$ & Frequency & $\%$ \\
\hline \multicolumn{7}{|l|}{ Sex } \\
\hline Male & 5 & 31.25 & 4 & 25 & 3 & 18.75 \\
\hline Female & 2 & 12.5 & N/A & N/A & 2 & 12.5 \\
\hline \multicolumn{7}{|l|}{ Age } \\
\hline Less than 35 years old & 1 & 6.25 & 1 & 6.25 & N/A & N/A \\
\hline $36-50$ years old & 3 & 18.75 & 3 & 18.75 & 3 & 18.75 \\
\hline $\begin{array}{l}\text { More than } 50 \text { years old } \\
\text { Seniority }\end{array}$ & 3 & 18.75 & N/A & N/A & 2 & 12.5 \\
\hline Less than 10 years & 1 & 6.25 & 1 & 6.25 & 1 & 6.25 \\
\hline $11-15$ years & 2 & 12.5 & 2 & 12.5 & 2 & 12.5 \\
\hline More than 15 years & 4 & 25 & 1 & 6.25 & 2 & 12.5 \\
\hline
\end{tabular}


expecting. With the upgrading of communication technology network, the functions of IoT system will be significantly improved while the price and cost will be gradually decreased, all of which can create an excellent basic environment for the promotion of the IoT applications.

For the conventional industry, the digital and intelligent transformation for the international commercial ports has become a realistic demand driven by the new generation of information technology. With the development trend of specialization and large-scale, more and more ports are carrying out the innovation towards to the automatic loading of terminals, intelligent cargo registration and digitalized safety supervision. This realistic demand is accurately consistent with the functions of IoT system. Due to the support by IoT technology, the management and business operation patterns of the international commercial ports will be genuinely reformed and reconstructed. In the future, ports will be constructed to a convenient, intelligent, open and shared ecosystem.

Therefore, this study starts from the perspective of exploring the feasibility of applying the IoT system to the international commercial ports, and a new framework of key success factors affecting the final effectiveness has been proposed. Based on the experts' suggestions, the initial framework has been divided into four main categories, namely the technological innovation (TI), support by the government (SG), social and economic values (SEV), experiencer's trust (ET), respectively. Among them, "Support by the Government (SG)" should be drawn more attention. Besides, to each evaluated sub-criteria, the operating standards for IoT system should be standardized globally is evaluated as a core factor for affecting the success of this application. This study also finds out that the government or relevant administrative departments should formulate some convenient and favorable policies to actively upgrade the port operation, which has also become an urgent demand at present. Meanwhile, in the current situation of over-utilization of resources, more and more managers pay more attention to the integration of resources. They particularly expect the new technology can guarantee the sustainable development of port operation.

\section{Acknowledgements}

This research is partially supported by the Key Project in Philosophy and Social Science Research of Ministry of Education of China (18JZD059), and the natural science research project of university in
Jiangsu (19KJB120009). The authors are also grateful to the comments and suggestions provided by anonymous reviewers.

\section{References}

[1] Nguyen HT, Ngo QD, Nguyen DH, Le VH. PSI-Rooted Subgraph: A Novel Feature for IoT Botnet Detection Using Classifier Algorithms. ICT Express 2020;6(2):128-38. https:// doi.org/10.1016/j.icte.2019.12.001.

[2] Casola V, Benedictis AD, Rak M, Villano U. Toward the automation of threat modeling and risk assessment in IoT systems. Internet of Things 2019;7:100056.

[3] Jorge G, Edmundo M, Jorge SS. Security for the internet of things: a survey of existing protocols and open research issues. IEEE Commun Surv Tutor 2015;1:1.

[4] Afghan SA, Géza H. Modelling and analysis of energy harvesting in internet of things (IoT): characterization of a thermal energy harvesting circuit for IoT based applications with LTC3108. Energies 2019;12(20):3873.

[5] Hassan MU, Rehmani MH, Chen JJ. Privacy preservation in blockchain based IoT systems: integration issues, prospects, challenges, and future research directions. Future Generat Comput Syst 2019;97:512-29.

[6] Pirmagomedov R, Koucheryavy Y. IoT Technologies for Augmented Human: a Survey. Internet of Things 2019;14: 100120. https://doi.org/10.1016/j.iot.2019.100120.

[7] Colaković A, Hadžialić M. Internet of Things (IoT): a review of enabling technologies, challenges, and open research issues. Comput Network 2018;144:17-39.

[8] Kumar NM, Mallick PK. Blockchain technology for security issues and challenges in IoT. Procedia Comput Sci 2018;132: 1815-23.

[9] Ammar M, Russello G, Crispo B. Internet of Things: a survey on the security of IoT frameworks. J Inf Secur Appl 2018;38: $8-27$.

[10] Jun WK, Lee MK, Choi JY. Impact of the intelligent port industry on the Korean national economy using input-output analysis. Transport Res Pol Pract 2018;118:480-93.

[11] Yigit K, Acarkan B. A new electrical energy management approach for ships using mixed energy sources to ensure sustainable port cities. Sustain Cit Soc 2018;40:126-35.

[12] Hsieh HC, Chen JL, Benslimane A5G. Virtualized multi-access edge computing platform for IoT applications. J Netw Comput Appl 2018;115:94-102.

[13] Liu L, Shi QF, Ho JS, Lee CK. Study of thin film blue energy harvester based on triboelectric nanogenerator and seashore IoT applications. Nano Energy 2019;66:104167.

[14] Sun MY, Zhou ZB, Wang JP, Du C, Gaaloul W. Energyefficient IoT service composition for concurrent timed applications. Future Generat Comput Syst 2019;100:1017-30.

[15] Glaroudis D, Iossifides A, Chatzimisios P. Survey, comparison and research challenges of IoT application protocols for intelligent farming. Comput Network 2020;168:107037.

[16] Chen YQ, Zhou B, Zhang MM, Chen CM. Using IoT technology for computer-integrated manufacturing systems in the semiconductor industry. Appl Soft Comput 2020;89: 106065. https://doi.org/10.1016/j.asoc.2020.106065.

[17] Shee TS, Gan GY, Lee HS, Chung CC, Wang QF. Critical success factors of internet of things application in Taiwan's international commercial ports. J Mar Sci Technol 2018;26(4): 487-95.

[18] Mourtzis D, Vlachou E, Milas N. Industrial big data as a result of IoT adoption in manufacturing. Procedia CIRP 2016; 55:290-5.

[19] Jabbar S, Ullah F, Khalid S, Khan M. Semantic interoperability in heterogeneous IoT infrastructure for healthcare. Wireless Commun Mobile Comput 2017;2017:1-10.

[20] Park C, Kim Y, Jeong M. Influencing factors on risk perception of IoT-based home energy management services. Telematics Inf 2018;35(8):2355-65. 
[21] Yamada Y, Shinkuma R, Iwai T, Onishi T, Satoda K. Temporal traffic smoothing for IoT traffic in mobile networks. Comput Network 2018;146:115-24.

[22] Ding L, Hu B, Ke CY, Wang TT, Chang S. Effects of IoT technology on gray market: an analysis based on traceability system design. Comput Ind Eng 2019;136:80-94.

[23] AlRukaibi F, AlKheder S, AlMashan N. Sustainable port management in Kuwait: shuwaikh port system. Asian J Ship Logis 2020;36(1):20-33. https://doi.org/10.1016/j.ajsl.2019.10.002.

[24] Hofmann W, Branding F. Implementation of an IoT- and cloud-based digital twin for real-time decision support in port operations. IFAC-PapersOnLine 2019;52(13):2104-9.
[25] Muñuzuri J, Onieva L, Cortés P, Guadix J. Using IoT data and applications to improve port-based intermodal supply chains. Comput Ind Eng 2020;139:105668.

[26] Tone K. A slacks-based measure of efficiency in data envelopment analysis. Eur J Oper Res 2001;130:498-509.

[27] Tone K. A slacks-based measure of super-efficiency in data envelopment analysis. Eur J Oper Res 2002;143:32-41.

[28] Saddoud A, Doghri W, Charfi E, Fourati LC. 5G radio resource management approach for multi-traffic IoT communications. Comput Network 2020;166:106936. 